\title{
Convective Heat Transfer During Melting in a Solar LHTES
}

\author{
Fatima Zohra Mecieb \\ Laboratory of Reactive Systems and Materials \\ University Djillali liabes of Sidi Bel Abbes \\ Sidi Bel Abbes, Algeria \\ fatima.mecieb@univ-sba.dz \\ Juan Pedro Solano Fernández \\ Thermal and Fluid Engineering Department \\ Polytechnic University of Cartagena \\ Cartagena, Spain \\ JuanP.Solano@upct.es
}

\author{
Francisco García Bermejo \\ Thermal and Fluid Engineering Department \\ Polytechnic University of Cartagena \\ Cartagena, Spain \\ pacoaitpaco@gmail.com \\ Samir Laouedj \\ Laboratory of Reactive Systems and Materials \\ University Djillali liabes of Sidi Bel Abbes \\ Sidi Bel Abbes, Algeria \\ s.laouedj@gmail.com
}

\begin{abstract}
Melting combined with natural convection in a shell and Latent Heat Thermal Energy Storage (LHTES) tube driven by a solar collector was analyzed numerically in the present work. This work's particularity lies in the fact that the HTF temperature varies at each moment following the solar irradiance curve. A program (UDF) has been developed and integrated into Ansys to meet this requirement. The use of this coupling strategy allows obtaining realistic unsteady LHTES results. Several numerical investigations were carried out to analyze the effect of the heat sources' power on the accumulator's performance. The obtained results show that natural convection considerably influences the heat transfer as well as the melting kinetics of the Phase Change Material (PCM). Besides, the results show that increasing the heat transfer fluid's thermal load can increase the melting rate of the PCM and the stored energy and reduce the entire melting time.
\end{abstract}

\section{Keywords-natural convection; solar coupling; PCM melting}

\section{INTRODUCTION}

Among the wide variety of renewable energy sources, solar energy is the largest one and simultaneously an example of a time-variable energy source that is mismatched with the needs of use. Energy storage is the most appropriate way to overcome these inadequacies. Although there are several storage systems, latent heat storage using Phase Change Material (PCM) has clear advantages over others: a greater density of energy storage and a relatively constant storage temperature. However, these materials present many problems because of their low thermal conductivity. Improving heat transfer by developing a useful heat exchanger device in the Latent Heat Thermal Energy Storage (LHTES) unit is a solution to the PCM's low thermal conductivity problem. This calls for a powerful knowledge of the heat transfer in the LHTES process. The absence of comprehension of heat transfer modes during the phase change is an issue frequently mentioned in the literature. Potential heat transfer mechanisms are convection, conduction, or a mixture of both. Therefore, the question which mode dominates at different melting levels has been discussed for decades $[1,2]$. Some authors thought that conduction took an essential part in phase transition operations [3, 4]. However, several researchers have reported that natural convection, especially during melting, is the essential heat transfer mode in phase transformation.

Among the first works carried out in this context, we can cite the experimental work in $[5,6]$ as well as the numerical simulations in $[7,8]$ that proved that natural convection could have a powerful impact on the rate of heat transfer and the form of the melting front. Later, authors in [9] developed a scale theory and identified the boundaries of the different regimes of the heat transfer mechanisms present in the melting of PCM in a laterally heated square enclosure. The research results demonstrated that the conduction heat transfer mechanism is dominant in the melting process's initial phases. The natural convection induced by the buoyancy of the liquid is intensified as melting progresses. They mentioned the existence of a transition region between these two. Several recent experimental and computational studies have shown that a mixture of conduction and convection is the heat transfer mechanism in an LHTES system [10-14].

As discussed above, the work concentrating on heat transfer with a fixed hot wall temperature in a basic LHTES device configuration was substantially different from the actual situation where the hot source's temperature is not constant. Thus, this paper focuses on PCM's heat transfer mechanics during the charging processes in the horizontal cylindrical shell-and-tubes LHTES system driven by a solar collector in which the temperature of the HTF changes every moment during the day according to a journal solar irradiation curve. 


\section{NUMERICAL SIMULATION}

\section{A. Physical Model}

Figure 1 shows a schematic illustration of a horizontal shell and tubes LHTES unit. The designed LHTES unit consists mainly of 12 stainless steel tubes with a $17.2 \mathrm{~mm}$ diameter and a thickness of $2.31 \mathrm{~mm}$. The heat transfer fluid flows in series through the inner tubes, and the PCM is uniformly distributed on the shell side.

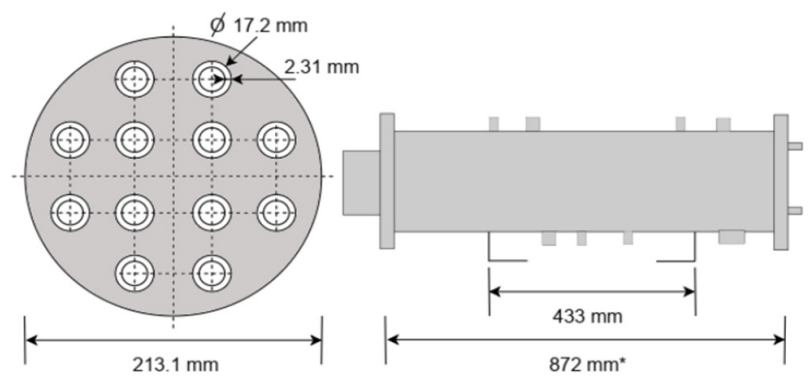

Fig. 1. Characteristic dimensions of the geometry.

The enthalpy-porosity method developed in [15] is employed in modeling and simulating the phase change process. In this method, the enthalpy $H$ is written as the sum of the sensible enthalpy $h_{\text {sensible }}$ and the latent enthalpy $h_{\text {latent }}$.

$$
H=h_{\text {sensible }}+h_{\text {latent }}
$$

with:

$$
h_{\text {sensible }}=h_{\text {ref }}+\int_{T_{\text {ref }}}^{T} C p . d T
$$

The latent heat enthalpy can vary between zero (for a solid) and $\Delta H_{L}$ (for a liquid).

$$
h_{\text {latent }}=L_{f} \cdot \Delta H_{L}
$$

The liquid fraction $L f$ can be defined as:

$$
\left\{\begin{array}{rlrl}
L_{f}=0 & T & <T_{\text {solidus }} \\
L_{f}=1 & \text { if } & T & <T_{\text {liquidus }} \\
L_{f}=\frac{T-T_{\text {solidus }}}{T_{\text {liquidus }}-T_{\text {solidus }}} & T_{\text {solidus }} & <T<T_{\text {liquidus }}
\end{array}\right.
$$

The correct characterization of material properties is one of the essential parts of performing simulations. The construction material of the accumulator is steel, whose characteristics are presented in Table I.

TABLE I. STEEL PROPERTIES

\begin{tabular}{|c|c|}
\hline Properties & Values \\
\hline Density $\left[\mathrm{kg} / \mathrm{m}^{3}\right]$ & 8030 \\
\hline Specific heat $[\mathrm{J} / \mathrm{kg} . \mathrm{K}]$ & 502.48 \\
\hline Thermal conductivity [W/m.K] & 16 \\
\hline
\end{tabular}

The other material to be defined in the system is the paraffin $\mathrm{RT} 70 \mathrm{HC}$, with a melting point around $70^{\circ} \mathrm{C}$. This paraffin is used as phase change material, storing the installation's solar collector's absorbed thermal energy. The principal reason for choosing paraffin wax is that its melting temperature conforms with the HTF temperature coming from the solar collectors at medium temperatures. This material has been analyzed and detailed correlations of the material's descriptive parameters have been provided in [16]. The melting and solidification temperatures of the paraffin and the latent thermal energy must be added to these correlations.

$$
\begin{gathered}
T_{\text {solidus }}=66.76^{\circ} \mathrm{C} \\
T_{\text {liquidus }}=78.85^{\circ} \mathrm{C} \\
\Delta H_{L}=244970 \mathrm{~J} / \mathrm{kg}
\end{gathered}
$$

Note that paraffin should be treated as a fluid that is initially in a solid-state.

\section{B. Initial and Boundary Conditions}

A two-dimensional domain is considered saving computational cost. Since there is no depth, there will be no HTF flow, and the boundary condition "convective heat transfer" is applied to the tubes' wall. Therefore, only the "free stream temperature" is considered. A UDF is employed to ensure the three-dimensional aspect of the solution by calculating the outlet temperature of each tube using the following equation:

$$
T_{\text {out }}=\frac{\dot{Q}}{\dot{m}_{H T F} \cdot C p_{H T F}}+T_{\text {in }}
$$

where $T_{i n}$ is the output temperature of the previous tube and $\dot{Q}$ is the heat that the PCM absorbed from the HTF at the current time which is calculated by:

$$
\dot{Q}=h_{\text {int }} . A\left(T_{f s}-T_{w}\right)
$$

The heat transfer coefficient $h_{\text {int }}$ between water and the internal tubes' walls is calculated in the UDF according to [17] by the following equations:

$$
\begin{gathered}
h_{\text {int }}=N u_{D} \frac{k_{H T F}}{D} \quad(7) \\
N u_{D}=\frac{(F / 8)(R e-1000) P r}{1+12.7(F / 8)^{1 / 2}\left(\operatorname{Pr}^{2 / 3}-1\right)}
\end{gathered}
$$

The correlation is valid for $0.5<P r<2000$ and $3000<\operatorname{Re}<5.10^{6}$.

The friction factor $F$ is calculated by:

$$
F=(1.58 \ln R e-3.28)^{-2}
$$

Initially, the solid PCM is at a temperature of $295^{\circ} \mathrm{K}$. The HTF flow rate in tubes is $1.84 \mathrm{~L} / \mathrm{min}$ with Reynold number $R e=3,089,37$. The heat in (6) is exploited to update the HTF temperature at the outlet of one tube (9) that corresponds to the boundary condition (inlet) temperature of the next tube.

Since a series flow is adopted, the fluid will flow from one tube to the other by gradually decreasing the temperature. At each time step, a different fluid temperature would be imposed for each tube, which implies calculating the solution in each of them. The accumulator will be directly connected to a solar collector (Figure 2), with an efficiency given by (10), (11) and an absorption surface of $A_{c o l}=3.03 \mathrm{~m}^{2}$. 


$$
\eta=0.514-1.158 . T_{\text {corr }}-0.005 . G . T_{\text {corr }}^{2}
$$

with:

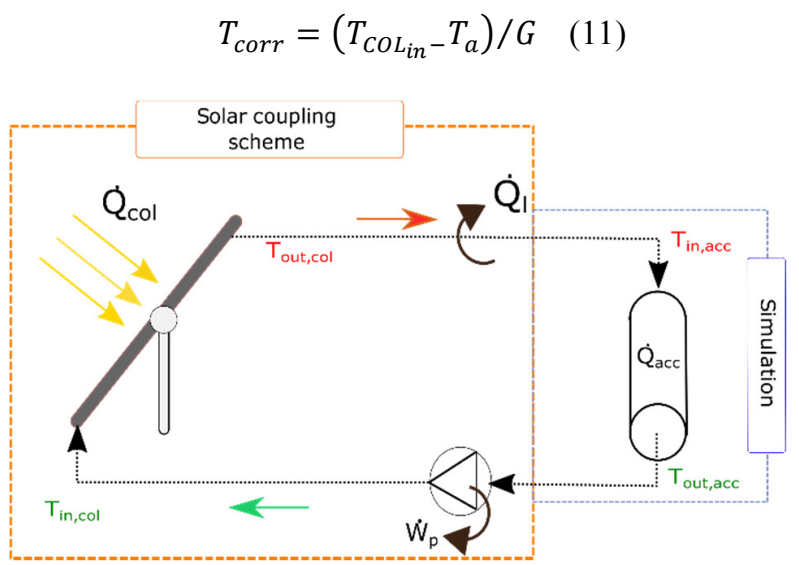

Fig. 2. Schematic diagram of the primary circuit of the installation.

As a general rule, under ideal conditions (without cloud interference), solar radiation can be expressed by a positive sinusoidal function whose period corresponds to the duration of the day. According to the Murcia region's climatic data (in the south of Spain), 3 solar curves can be formed depending on the period (winter, mixed, and summer). The heat is ideally absorbed by the solar collector per unit area, $G$.

$$
\begin{aligned}
& G=270 \cdot\left(1-\cos \left(\frac{\pi \cdot t}{18000}\right)\right) \\
& G=392 \cdot\left(1-\cos \left(\frac{\pi \cdot t}{21000}\right)\right) \\
& G=480 \cdot\left(1-\cos \left(\frac{\pi \cdot t}{27000}\right)\right)
\end{aligned}
$$

The progressive rise of the accumulator fluid inlet temperature, as a function of the irradiation dynamics involved in (12)-(14), drives the storage of thermal energy in the PCM accumulator through a solar coupling algorithm programmed in the UDF. Equation (15) gets the temperature at the solar collector's output at each moment:

$$
T_{C O L_{\text {out }}}=T_{C O L_{\text {in }}}+Q_{C O L} \cdot \dot{m}_{H T F} \cdot C p_{H T F}
$$

with:

$$
Q_{\mathrm{COL}}=A_{\mathrm{COL}} \cdot G \cdot \eta
$$

The resulting temperature of the HTF at the solar collector outlet will be specified at the storage system inlet. The solar coupling scheme will update the heat-transfer fluid's temperature at each moment, considering the solar radiation using the algorithm described above.

\section{Numerical Procedure}

Considering the shell-and-tube LHTES design, hexahedron quad and map elements are adopted to discretize the PCM domain. The cells near the inner tube are refined to get accurately the velocity and temperature gradients. The secondorder discretization scheme is used for the momentum and energy equations' spatial discretization to have higher accuracy in the solution. A pressure-velocity coupling by the algorithm
SIMPLEC is applied in this calculation, with a modification of the under-relaxation factors. The following simplifications are applied to the 2D model:

- The liquid paraffin and the heat transfer fluid are incompressible Newtonian fluids.

- PCM is assumed to be isotropic and homogeneous and the volumetric expansion of PCM during melting is neglected.

In the present simulation, the boundary condition by convective heat transfer and the strategies followed for the coupling of the solar curve by UDF represent the fundamental basis for this accumulator's modeling. The system's performances are analyzed by modifying the thermal load of the HTF through varying the irradiance curve according to the climatic conditions.

\section{VALIDATION}

The simulation results are compared with the experimental data from [16] to verify the actual numerical simulations. The comparison of measured irradiation and liquid fraction and the simulation results for the cases of a sunny day of May 31, 2019 are shown in Figure 3. A reasonable agreement can be seen between the numerical and the experimental results (with a maximum liquid fraction absolute error of 0.1812), confirming the combined enthalpy porosity and natural convection model's feasibility in the present investigation.

\section{RESULTS AND DISCUSSION}

\section{A. Comparison of Conduction and Conduction-Convection Models}

Figures 4 and 5 show the temperature and liquid fraction contours in the storage tank's paraffin, whose heat is supplied by two solar collectors for a winter curve. The melting process is simulated using a convection and conduction model and a pure conduction model. As illustrated in Figure 4(a), the temperature contours are symmetrical along the horizontal and vertical axes. The conduction heat transfer mechanism could interpret that. The phase change material temperature is monitored by the energy absorbed from the HTF by the PCM. Thermal energy is transmitted from the hot paraffin to the adjacent layer of cold paraffin. The temperature at one location in the accumulator could remain stable or increase depending on the two energy transfer processes' rates. The total heat transfer rate in the conduction model seems to be the same in all directions. The melting front in the radial direction passes from the tube wall to the shell's internal surface at the same velocity (Figure 5(a)). Nevertheless, the results found from the convection-conduction model are distinct. Figure 4(b) displays the temperature contours through the melting phase. The PCM temperature varies considerably in the vertical axis at distinct moments during the melting process. In the convectionconduction model, heat transfer from the tube surface to the PCM proceeds the conduction just before PCM begins to melt. As the paraffin melts, a thin liquid film forms between the tubes' outer wall and the solid PCM and natural convection begins to occur. As the molten area expands, the convection gets more significant, and the interface front moves quicker (Figure 5(b)). 

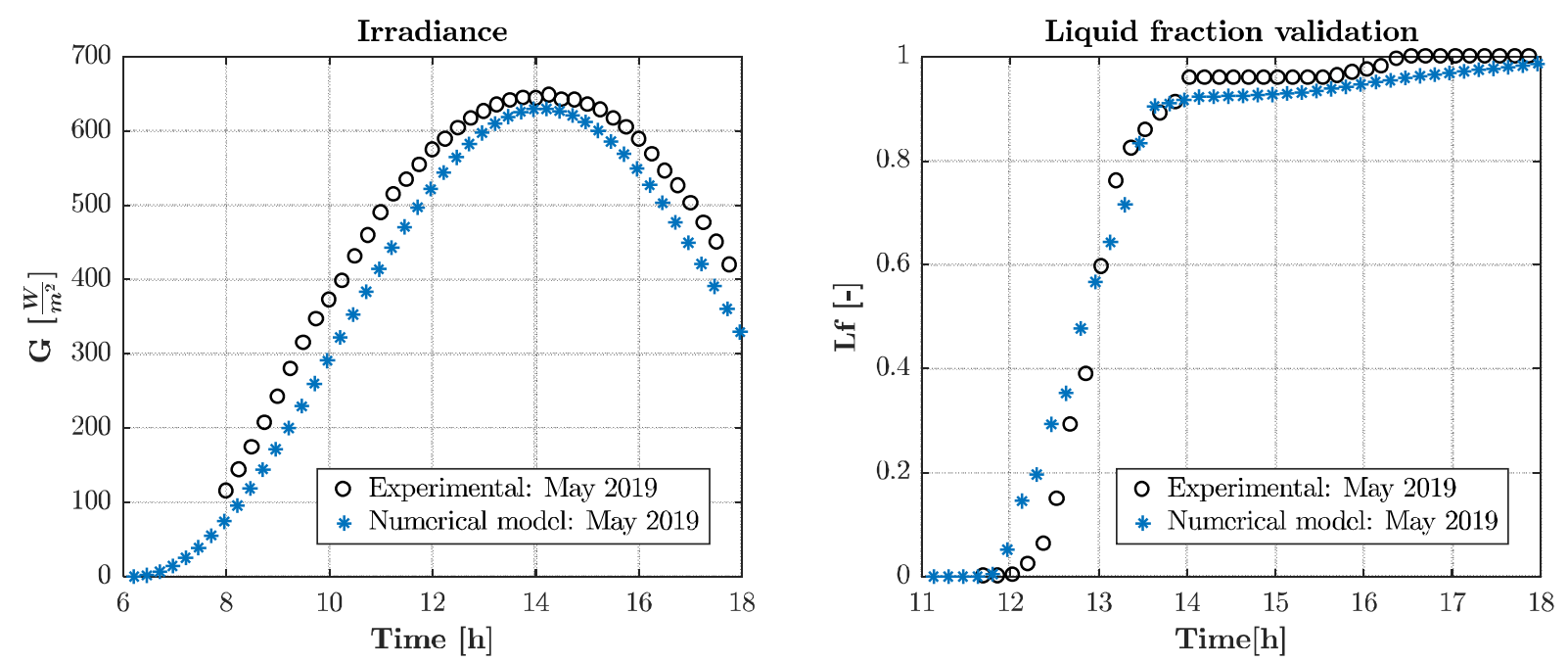

Fig. 3. Irradiance and PCM liquid fraction by current numerical model in comparison with the experimental resutls of [16].

As shown in Error! Reference source not found.(b), the liquid PCM increases and progressively occupies the storage tank's upper section due to buoyancy. In the top zone of the accumulator, PCM takes less time to melt than the bottom. This result is compatible with that reported in [16]. (a)

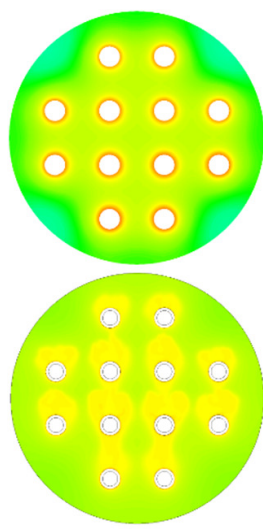

$11 \mathrm{AM}$
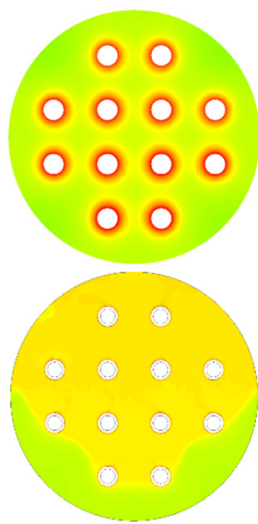

12 AM
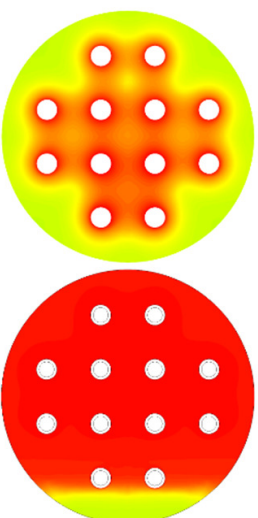

2 PM

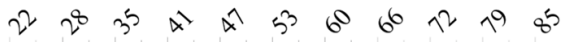

Fig. 4. Temperature contours: (a) conduction model, (b) convectionconduction model.

\section{B. Nusselt Number.}

Nusselt identifies the relationship between convective and conductive heat transmission. It is expressed according to (17):

$$
N u=\frac{h_{\text {conv }} \cdot D}{k}
$$
that:

The convection coefficient on this LHTES side $h_{\text {conv }}$ is such

$$
h_{\text {conv }}^{i}=\frac{\dot{q}^{i}}{\bar{T}_{w}^{i}-\bar{T}_{f, P C M}^{i}}
$$

(a)
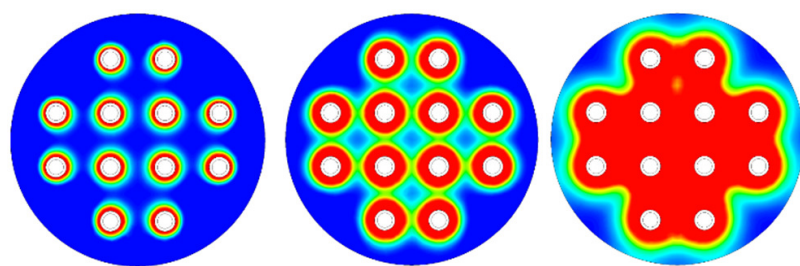

(b)

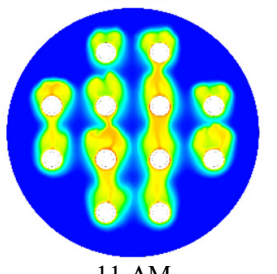

$11 \mathrm{AM}$

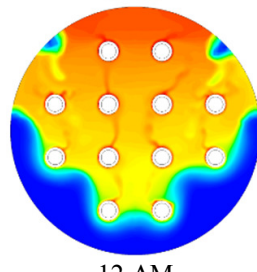

$12 \mathrm{AM}$

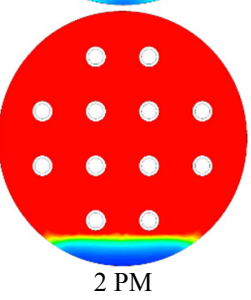

인

Fig. 5. Liquid fraction contours: (a) conduction model, (b) convectionconduction model.

At each moment, only the fluid portion (liquid) of the PCM is considered getting an average PCM liquid temperature value, $\bar{T}_{f, P C M}^{i}$.

Figure 6 shows the solution obtained for the simulations using different solar curves. The Nusselt number is represented as a function of dimensionless time $\theta$, which is given by:

$$
\theta=\text { Fo.Ste }
$$

The temporal evolution of the Nusselt number is represented as a function of different heat transfer regimes (Figure 6):

- A pure conduction regime for $\theta>0$ (corresponding to zone I). As the temperature gradient initially has significant values due to the increased tube wall temperature, the Nusselt number decreases quickly within the initial melting step. The weak heat transfer, distinguished by a monotonous drop of the Nusselt number, is the particularity of this conduction regime. 
- A mixed convection-conduction regime for $0.017 \leq 0 \leq 0.043$ (corresponding to zone II) where the conduction process is gradually replaced by convection. One crucial finding associated with convection melting is that the impact of natural convection ascends with $\theta$ [9].

- A convection-dominated regime for $\theta>0.043$ (corresponding to Zone III). Within the asymptotic limit of $\theta$, we can get the simplified $N u$ law $\sim R a^{1 / 4}$ [9]. The plateau at $R a^{1 / 4}$ refers to pure convective heat transfer and is shown in Figure 6 for $0.043<\theta<0.11$. Besides, the average Nusselt number between the heated tubes and the PCM liquid zone is relatively independent of time in the convectiondominated regime. Therefore, the convection-dominated regime is also known as the "quasi-steady" regime.

- The numerical results indicate a decrease of $N u$ in the ultimate phase $(\theta>0.11)$ when the liquid PCM fills the majority of the accumulator $\left(L_{\rho}>0.8\right)$ (corresponding to zone IV). Stratification dominates in this advanced evolution of the melting process.
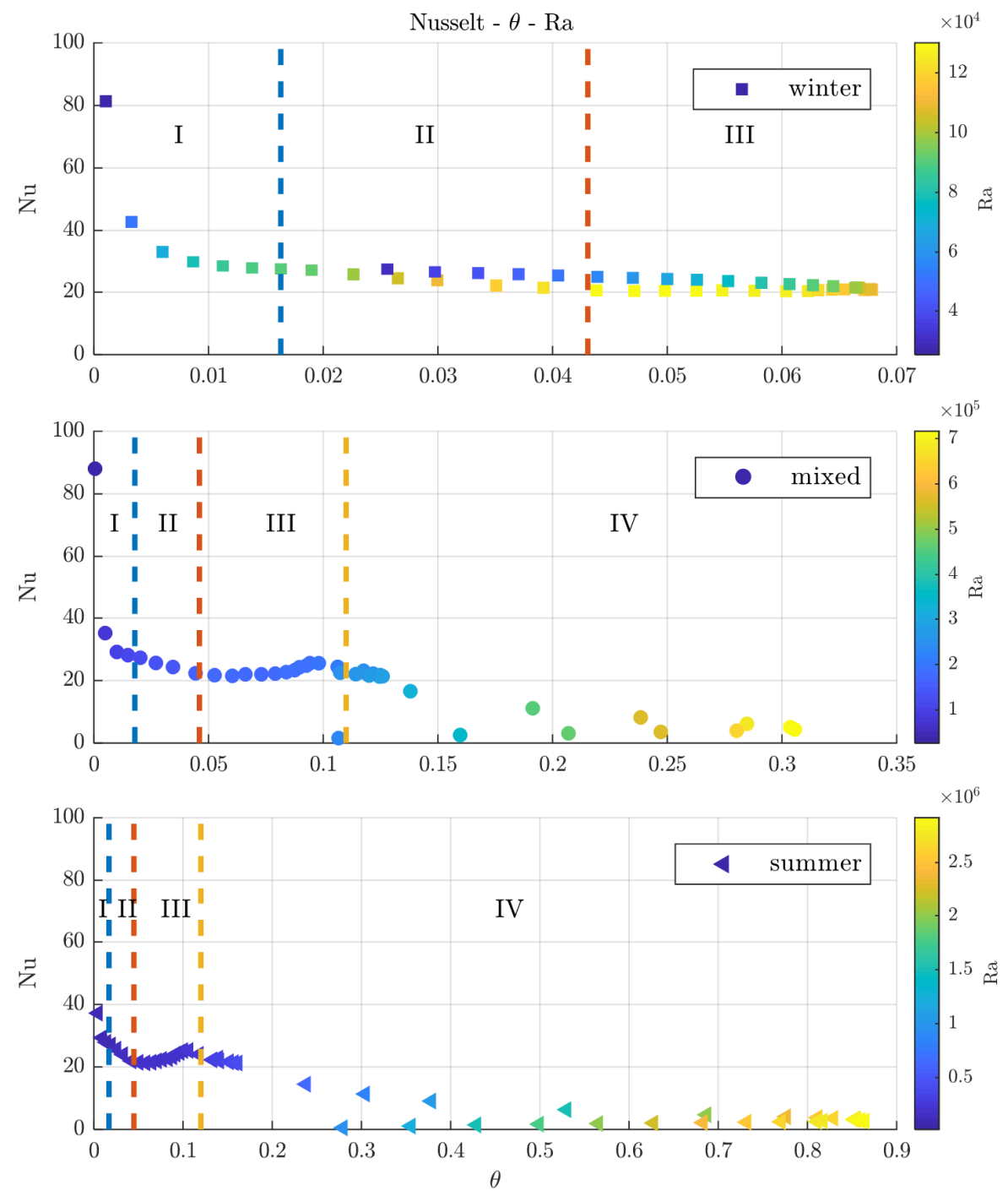

Fig. 6. Nusselt number according to $\theta$.

\section{CONCLUSION}

A paraffin melting process has been carried out in a tubeand-shell LHTES integrated with a solar collector. The results can be summarized as follows:

- In the convection-conduction model's temperature field, the rise in temperature in the shell's upper zone was faster than in the low zone, whereas in the conduction model, there was a simultaneous rise in temperature at the shell's top and bottom. The convection-conduction model better interprets the heat transfer mechanism during PCM melting.

- The performance of the LHTES in summer conditions is higher than in mixed and winter conditions, but the PCM 
temperature exceeds $100^{\circ} \mathrm{C}$, which must be avoided to prevent PCM degradation.

- The melting of the complete paraffin passes via 4 regimes, and each regime has its own Nusselt number. The relation between the Nusselt number and dimensionless time initially indicates a significant drop (conduction), a transition (conduction and convection), a plateau (convection), and, eventually, a gradual decrease towards the disappearance of the solid (stratification).

$\begin{array}{cl} & \text { NOMENCLATURE } \\ D & \text { Diameter }(\mathrm{m}) \\ C p & \text { Specific heat capacity }\left(\mathrm{J} \cdot \mathrm{kg}^{-1} \cdot \mathrm{K}^{-1}\right) \\ F O & \text { Fourier number, } F o=\frac{\alpha \cdot t}{D^{2}} \\ \Delta H L & \text { Latent heat }\left(\mathrm{J} \cdot \mathrm{kg}^{-1}\right) \\ k & \text { Thermal conductivity }\left(\mathrm{W} \cdot \mathrm{m}^{-1} \cdot \mathrm{K}^{-1}\right) \\ \dot{m} & \text { Mass flow }\left(\mathrm{kg} \cdot \mathrm{h}^{-1}\right) \\ P r & \text { Prendtl number } \\ T & \text { Température }(\mathrm{K}) \\ \bar{T} & \text { Average temperature }(\mathrm{K}) \\ T_{w} & \text { Wall temperature }(\mathrm{K}) \\ \text { Ste } & \text { Stefan number, Ste }=\frac{C p \cdot \Delta T}{\Delta H_{L}} \\ t & \text { Time }(\mathrm{s}) \\ \alpha & \text { Thermal diffusivity }\left(\mathrm{m}^{2} \cdot \mathrm{s}^{-1}\right) \\ \mu & \text { Viscosity, } \mathrm{kg} \cdot \mathrm{m}^{-1} \cdot \mathrm{s}^{-1} \\ \rho & \text { Density }\left(\mathrm{kg} \cdot \mathrm{m}^{-3}\right)\end{array}$

\section{REFERENCES}

[1] H. $\mathrm{Hu}$ and S. A. Argyropoulos, "Mathematical modelling of solidification and melting: a review," Modelling and Simulation in Materials Science and Engineering, vol. 4, no. 4, pp. 371-396, Jul. 1996, https://doi.org/10.1088/0965-0393/4/4/004.

[2] Y. Dutil, D. R. Rousse, N. B. Salah, S. Lassue, and L. Zalewski, "A review on phase-change materials: Mathematical modeling and simulations," Renewable and Sustainable Energy Reviews, vol. 15, no. 1, pp. 112-130, Jan. 2011, https://doi.org/10.1016/j.rser.2010.06.011.

[3] N. B. Khedher, "Numerical Study of the Thermal Behavior of a Composite Phase Change Material (PCM) Room," Engineering, Technology \& Applied Science Research, vol. 8, no. 2, pp. 2663-2667, Apr. 2018, https://doi.org/10.48084/etasr.1824.

[4] Z. Tan, K. M. Lim, and B. C. Khoo, "An adaptive mesh redistribution method for the incompressible mixture flows using phase-field model," Journal of Computational Physics, vol. 225, no. 1, pp. 1137-1158, Jul. 2007, https://doi.org/10.1016/j.jcp.2007.01.019.

[5] E. M. Sparrow, S. V. Patankar, and S. Ramadhyani, "Analysis of Melting in the Presence of Natural Convection in the Melt Region," Journal of Heat Transfer, vol. 99, no. 4, pp. 520-526, Nov. 1977, https://doi.org/10.1115/1.3450736.

[6] C. Benard, D. Gobin, and F. Martinez, "Melting in Rectangular Enclosures: Experiments and Numerical Simulations," Journal of Heat Transfer, vol. 107, no. 4, pp. 794-803, Nov. 1985, https://doi.org/ 10.1115/1.3247506.

[7] H. Rieger, U. Projahn, M. Bareiss, and H. Beer, "Heat Transfer During Melting Inside a Horizontal Tube," Journal of Heat Transfer, vol. 105, no. 2, pp. 226-234, May 1983, https://doi.org/10.1115/1.3245567.

[8] M. Okada, "Analysis of heat transfer during melting from a vertical wall," International Journal of Heat and Mass Transfer, vol. 27, no. 11, pp. 2057-2066, Nov. 1984, https://doi.org/10.1016/0017-9310(84) 90192-3.

[9] P. Jany and A. Bejan, "Scaling theory of melting with natural convection in an enclosure," International Journal of Heat and Mass Transfer, vol. 31 , no. 6, pp. 1221-1235, Jun. 1988, https://doi.org/10.1016/00179310(88)90065-8.
[10] X. Sun, Y. Chu, Y. Mo, S. Fan, and S. Liao, "Experimental investigations on the heat transfer of melting phase change material (PCM)," Energy Procedia, vol. 152, pp. 186-191, Oct. 2018, https://doi.org/10.1016/j.egypro.2018.09.079.

[11] A. Memon, G. Mishra, and A. K. Gupta, "Buoyancy-driven melting and heat transfer around a horizontal cylinder in square enclosure filled with phase change material," Applied Thermal Engineering, vol. 181, Nov. 2020, Art. no. 115990, https://doi.org/10.1016/j.applthermaleng.2020. 115990.

[12] N. Mallya and S. Haussener, "Buoyancy-driven melting and solidification heat transfer analysis in encapsulated phase change materials," International Journal of Heat and Mass Transfer, vol. 164, Jan. 2021, Art. no. 120525, https://doi.org/10.1016/j.ijheatmasstransfer. 2020.120525 .

[13] A. S. Soliman, S. Zhu, L. Xu, J. Dong, and P. Cheng, "Numerical simulation and experimental verification of constrained melting of phase change material in cylindrical enclosure subjected to a constant heat flux," Journal of Energy Storage, vol. 35, Mar. 2021, Art. no. 102312, https://doi.org/10.1016/j.est.2021.102312.

[14] M. A. Aichouni, N. F. Alshammari, N. B. Khedher, and M. Aichouni, "Experimental Evaluation of Nano-Enhanced Phase Change Materials in a Finned Storage Unit," Engineering, Technology \& Applied Science Research, vol. 10, no. 3, pp. 5814-5818, Jun. 2020, https://doi.org/ 10.48084/etasr.3616.

[15] V. R. Voller and C. Prakash, "A fixed grid numerical modelling methodology for convection-diffusion mushy region phase-change problems," International Journal of Heat and Mass Transfer, vol. 30, no. 8, pp. 1709-1719, Aug. 1987, https://doi.org/10.1016/00179310(87)90317-6.

[16] A. Egea, J. P. Solano, J. Pérez-García, and A. García, "Solar-driven melting dynamics in a shell and tube thermal energy store: An experimental analysis," Renewable Energy, vol. 154, pp. 1044-1052, Jul. 2020, https://doi.org/10.1016/j.renene.2020.03.078.

[17] F. P. Incropera, D. P. DeWitt, T. L. Bergman, and A. S. Lavine, Fundamentals of Heat and Mass Transfer, 6th ed. Hoboken, NJ, USA: John Wiley \& Sons, 2006. 